\title{
INVIGORATING ENTREPRENEURIAL SPIRIT AMONG WORKFORCE
}

\author{
Al Mutairi Aned $0^{1 *}--$ Al Mutairi Alya O. ${ }^{2}$ \\ ${ }^{1,2}$ School of Mathematical Sciences, Universiti Sains Malaysia, Penang, Malaysia
}

\begin{abstract}
With the key intent of stimulating entrepreneurial spirit among the workforce, this paper identifies the diverse entrepreneurial qualities required to propel the entrepreneurial spirit unremittingly. These relevant personal skills and strategies of New Venture Creation further aid in the successful creation and subsequent maintenance of an entrepreneur business. Prior to application of the identified skills, this paper vividly demonstrates the importance of such skills to any entrepreneurial business entity. This helps in New Venture Creation whilst aiding the businesses' sustainability. Therefore, the through proper application of the knowledge attained as well as skills identified, the entrepreneur manages to depict dynamism by consistently exploring different entrepreneurial opportunities. Although these skills tremendously boost the entrepreneur's spirit, they also create opportunities for the business to explore new and diverse opportunities thus circling back to enhancing entrepreneurial spirit. Furthermore, the paper seeks to make out the possible ways of constantly improving these entrepreneurial skills and in turn encouraging their adoption and consequent utilization among workforce. Further incorporation of knowledge attained from research projects on organizational climate, management support and reward and resource availability similarly focuses the paper to invigorating entrepreneurial spirit among workforce.
\end{abstract}

Keywords: Internal ecosystem, Intrapreneurial, Innovation, Reward management, recognition.

Received: 15 June 2013/ Revised: 20 June 2013/ Accepted: 22 June 2013 / Published: 25 June 2013

\section{INTRODUCTION}

An entrepreneur is an individual who takes up the participative identification of a business opportunity, organizes a venture and assumes the risk of undertaking the business. It takes proactive behavior in self-starter entrepreneurs to engage in effective generation of new ideas. Therefore, entrepreneurial spirit refers to the triggering nature that drives entrepreneurs to identifying business ideas and persistently taking risks towards making them productive. With this regard, entrepreneurial spirit profoundly influences entrepreneurship in the work force since it gives them the reason and ability to persist through intensive risks while still giving 
outstanding efforts towards the expected growth of their businesses. Subsequently, entrepreneurial spirit also plays a crucial role in the sustenance of a developed business through the provision of ideas on how to counter the immensely opposing market factors. Thus, the factors explained here serve the purpose of enhancing entrepreneurial spirit among workforce that in turn aids the effective creation and sustenance of entrepreneur businesses.

\section{DISCUSSION}

\subsection{Passion}

At the outset, passion best instills and maintains the entrepreneurial spirit in entrepreneurs that in turn inspires them to be more than they perceived themselves. Passion refers to the enthusiasm depicted by an entrepreneur with regard to their product or service. It ensures extreme excitement of the entrepreneur whenever they speak about their product or service to other people; to the extent that it triggers chilling emotions backed by thrilled body languages. Passion invigorates entrepreneurial spirit in entrepreneurs through its ability to facilitate growth and productivity of the business. With this essential skill of passion, entrepreneurs manage to convince other people on the advantages of their product or service thus attracting investors or customers. Similarly, it creates a path for the entrepreneur to pursue their business opportunities despite the resources available to them at that respective moment. The most crucial factor that drives entrepreneurs through the challenging process of creation and sustenance of a business is the realization of positive results and illustrations of constantly improving productivity. This gives more hope to the entrepreneur as well as a reason to continue resourcing the business past daily obstacles. In other words, passion positively enhances entrepreneurial spirit amongst workforce thus aiding unremitting desire for success.

\subsection{Internal Ecosystems}

According to Antoncic and Hisrich (2003), internal ecosystems boost entrepreneurial spirit and behavior in the workforce. In turn, heightened entrepreneurial spirit results to better job performance thus realization of better results. The dynamism of the business landscape in the present-day exerts more pressure on businesses thus calling for increased entrepreneurial spirit. It helps sustain any entrepreneurial business whilst providing innovative and high quality goods or services. Innovation involves a process derived from creative thinking that contributes to the development of entrepreneurial capability (Gilbertson, 2002). Innovative behavior starts with the process of opportunity exploration that allows individuals to research and discover any available opportunities. These opportunities vary from identified problems requiring solutions to similar conditions in desperate demand for immediate response. Secondly, idea generation illustrates an entrepreneur's capability to analyze the disparities in need of solutions and enact effective ideas on how to counter them. Through the process of countering them, the entrepreneur places themselves in business thus earning their results for as long as the disparity persists. Application 
of these ideas thus involves practical transfer into predetermined actions that fully exploit the opportunity both to the entrepreneur and to the victims of the disparity. Following to this, entrepreneurial spirit plays a vital role in entrepreneurship.

\subsection{Organizational Climate}

Organizational climate influences entrepreneurial spirit amongst the workforce through the depiction by the organizational norms and values (Ivancevich and Matteson, 2005). In that, an organization or group adopts entrepreneurship values of the workforce affiliated to it and learns to behave in a similar manner and demonstrating similar values. Gilbertson (2002) argues that with the intent to foster heightened entrepreneurial spirit among workforce and facilitate dynamism of new ideas, teams within the workforce ought to be created. Appreciation of creativity resulting to generation of new ideas characterizes these teams thus directly reflecting the sub-teams' actions to the entirety of the workforce. Best illustrated by Maslow's theory of hierarchical order of needs, feelings of belonging and affiliation trigger motivation in individuals thus initiating behaviors acceptable by other members. With this regard, creation of entrepreneurial spirit in significantly smaller groups triggers effective results amongst the workforce as compared to an attempt focusing on the entire workforce at once.

\subsection{Internal Cooperation}

In a socially stable workforce, internal cooperation backboned by the employees' willingness to participate in teamwork essentially boosts entrepreneurial spirit amongst them (Wunderer, 2001). The most essential elements that foster the inculcation of this entrepreneurial spirit in workforce settings include creative problem and subsequent operative ability to implement the ideas generated as an effective counter action. Relevantly, this approach allows freedom for teams in the workforce to decide on the self-organized means of completing their tasks. This ecosystem also encourages learning amongst the workforce through combining efforts towards developing new ideas and positively perceiving mistakes as step stones towards success. Most importantly, the aspect of accepting mistakes in the workforce but utilizing the knowledge to avoid similar mistakes in the future fosters heightened entrepreneurial spirits. In depth, internally contextual variables such as perception of the workforce as well as the existent communication climate tremendously influence the workforce's entrepreneurial spirit. Maintenance of these variables on the positive edge ensures unremitting entrepreneurial spirit proliferation amongst the workforce. As a result, establishment of a positive organizational climate supports innovativeness in the workforce thus stimulating enhanced entrepreneurial spirit since the environment enables them to engage in innovative activities freely.

\subsection{Organizational Support}

Furthermore, Hornsby et al. (2002) point out that organizational support of the workforce similarly influences entrepreneurial spirit positively. Playing a pivotal role, provision of a 
supportive work climate that allows the workforce to depict entrepreneur behavior as they undertake their tasks effectively facilitates entrepreneurial spirit. Additionally, such an organizational structure sees through the realization, adoption and implementation of an innovative culture. Evidently, work environments depicting psychological safety to the workforce permits enhanced creativity amongst them (Hornsby et al., 2002). Factors such as allowance of individuals to undertake certain risks with the key intent of innovative ideas and minimal negative feedback from other persons characterize these psychologically safe environments. Creativity forms the backbone of entrepreneurship as it sharpens the entrepreneur's mind giving them a different perception of the existent disparities; a perception that instead of looking at the negative results of existent problems focuses on development of counter actions that incorporate realization of profits. Otherwise, lack of creativity in entrepreneurs translates to theft of ideas amongst themselves or repetition of already implemented ideas. As a result, the ideas show no effect in their applications thus depreciating the entrepreneurial spirit amongst entrepreneurial workforce. Further demonstrated through a research project conducted on organization climate by Bhardwarj et al. (2007), a flexible organizational climate in any setting encourages entrepreneurial spirit amongst the workforce. This is because of the sole reason that the work's autonomy in the performance of obligatory tasks as well as in decision-making processes instills in the workforce a sense of independence. Consequently, the mentality of being in control backed by the absence of preset operating procedures and demanding administrative processes enhances critical thinking through all endeavors of the workforce. In the end, this approach invigorates entrepreneurial spirit in the workforce despite the entrepreneurial level in concern.

\subsection{Management Support}

Similarly, another factor that markedly influences entrepreneurial spirit amongst any workforce setting is management support. De Jong and Wennekers (2008) assert that leadership plays an influential role with regard to influencing entrepreneurial spirit amongst workforce. According to their argument, the top management comprises the leadership in the context; that either supports or undermines the ideas from the workforce. Boosted entrepreneurial spirit arises from encouragement of the workforce by the leadership through persistence in the need to generate new and innovative ideas on how to undertake their assigned tasks. Their research illustrates the need for the leaders to lead exemplary leadership to the extent that the workforce admires them thus gaining the urge to lead similar entrepreneurial lives. This triggers the workforce's innovative behavior, which the leaders further build through constant communication and unremitting support. In turn, this creates feeling of positivity in the workforce's endurance thus developing a mental stand that only demands and works towards successful results. This mirrors enhanced entrepreneurial spirit in the workforce that further strengthens tenacity. Tenacity is the urge for entrepreneurs to go get whatever they focus on. This trait promotes entrepreneurial spirit through elimination of fear in undertaking risks as it instills a conquering drive in the workforce. In other words, tenacity gives reasons to persist and value the entrepreneurial skills beyond doubt. Consultation of the workforce before making any decisions that may affect them serves as an example of a management practice 
that supports innovative culture. This consultation practice creates an opportunity for the workforce to participate actively in decision-making processes through the development of ideas and suggestions for consideration and perhaps incorporation. In the same way, delegating demonstrates positive management support aimed at invigorating entrepreneur spirit amongst workforce. Delegating refers to the active approach by the management to provide the workforce with autonomy to carry out their assigned tasks. This approach requires management to assign each member of workforce to their tasks; in that all organizational tasks have an individual responsible for their performance. Subsequently, the management leaves the rest to the workforce and waits for the projected results. This places an individual obligation to the workforce to perform their tasks productively, with the objective of contributing to the general objective of the organization for instance, realization of set targets. However, erroneous application of this approach results to failure in achievement of the organizational targets thus depreciated productivity of the workforce. Lack of cooperation and laziness of the workforce mainly characterize the factors leading to this failure. Consequently, such results contribute to decreased entrepreneurial spirit in the workforce.

With this regard, demonstration of friendliness with the workforce, patience with their task performance and improvement rates and listening to the workforce also promotes entrepreneurial spirit through support for their innovation. Allowance of mistakes and their subsequent consideration as a learning process illustrates a positive management support aimed at boosting up entrepreneurial spirit amongst the workforce. Holt et al. (2007) further clarified the link between management support and increased entrepreneurial spirit through a research that demonstrated a directly proportional relationship. In that, better management support to the workforce illustrated increasing trends of entrepreneurial spirit amongst workforce. Increased ideas and risks to implement these ideas illustrated the increase in entrepreneurial spirit amongst the workforce.

\subsection{Availability of rewards and resources}

Lastly, yet importantly, reward and resource availability boosts entrepreneurial spirit in organizations through promoting freedom for generation of ideas and subsequently allocating the necessary applicable resources to aid the innovation. Moreover, rewards over successful experiments of brilliant ideas facilitate both creativity and innovativeness amongst workforce. Availability of time, financial and physical resources foster the workforce's involvement in innovative activities (Chang, 1998). Large organizations with abundant resources create the opportunity to materialize the workforce's ideas thus illustrating higher levels entrepreneurial spirit. However, even for significantly smaller workforce's, entrepreneurial spirit may be invigorated through proper allocation of the available resources to aid in the nurturing of the proposed ideas. Likewise, better relationships between the management and the workforce enhance better understanding thus ensuring fair allocation of the available resources and rewards of the notable performances (De Jong, 2007). For instance, implementation of proposed ideas calls for support through funding and allocation of relevant resources to which the absence suppresses the entrepreneurial spirit of the workforce. On the other hand, availability of resources backed by rewards positively stimulates entrepreneurial spirit amongst workforce. 


\section{CONCLUSION}

In conclusion, different approaches serve the purpose of invigorating entrepreneurial spirit among workforce, which in turn aids heightened productivity hence better realization of set targets and objectives. With this regard, the explained approaches as well as additional discoveries ought to be incorporated to contribute to the enhancement of entrepreneurial spirit effectively amongst workforce.

Funding: This study received no specific financial support.

Competing Interests: The authors declare that they have no competing interests.

Contributors/Acknowledgement: All authors contributed equally to the conception and design of the study.

\section{REFERENCES}

Antoncic, B. and R.D. Hisrich, 2003. Clarifying the intrapreneurship concept. Journal of Small Business and Enterprise Development, 10(1): 7-24.

Bhardwarj, B.R., Sushil. and K. Momaya, 2007. Corporate entrepreneurship: Application of moderator method. Singapore Management Review, 29(1): 47-58.

Chang, J., 1998. Model of corporate entrepreneurship: Intrapreneurship and exopreneurship. Borneo Review, 9(2): 187-212.

De Jong, J. and S. Wennekers, 2008. Intrapreneurship: Conceptualizing entreprenuerial employee behaviour. Scales Research Reports H200802, EIM Business and Policy Research.

De Jong, J., 2007. Individual innovation: The connection between leadership and employees' innovative work behaviour. Phd Thesis, Zoetermeer: EIM.

Gilbertson, D., 2002. Public service innovation concepts. Innovative Processes Ltd.

Holt, D.T., W.M. Rutherford and C.G. R., 2007. Corporate entrepreneurship: An empirical look at individual characteristics, context and process. Journal of Leadership \& Organizational, $13(4): 40-54$.

Hornsby, J.H., D.F. Kuratko and Z.S. A., 2002. Middle managers' perception of the internal environment for corporate entrepreneurship: Assessing a measurement scale. Journal of Business Venturing, 17: 253-273.

Ivancevich, J.M.R. and M.T. Matteson, 2005. Organizational behavior and management (7th ed.). New York: NY: McGraw-Hill/Irwin.

Wunderer, R., 2001. Employees as "co-intrapreneurs"- a transformation concept. Leadership \& Organization, 22(5): 193-211. 